\title{
PERANCANGAN SISTEM PENDINGIN THERMO ELECTRIC COOLING BERBASIS MIKROKONTROLER AT89C51
}

\author{
Agus Basukesti \\ Sekolah Tinggi Teknologi Adisutjipto \\ J1. Janti Blok-R Lanud Adi \\ e-mail: agus_basukesti@yahoo.com
}

\begin{abstract}
Abstrak
Tulisan ini akan membahas manfaat thermo electric cooling sebagai pendingin dengan dukungan Mikrokontroler sebagai pengendali otomatis. Rancangan dapat dimanfaatkan pada sistem pengendalian peralatan, kinerja sistem terpengaruh panas, sistem-sistem lain yang berbaya jika bekerja pada suhu tinggi, serta dikendalikan dari jarak jauh. Kebutuhan perangkat keras rancangan ini adalah thermo electric cooling, Mikrokontroler AT89C51, IC LM 35, A/D Converter, penampil, dan Regulator 7805 serta didukung bahasa Assembler earth.asm. Sebelum perancangan dilaksanakan pengujian peralatan-peralatan, supaya sistem dapat berjalan dengan baik dan sesuai dengan fungsinya masing-masing. Untuk mengetahui kinerja sistem pendingin ini dengan cara mengamati data hasil simulasi pada tiga keadaan kondisi suhu prosesor dan heatsink prosesor pertama menggunakan heatsink standar, kedua water block dan ketiga water block ditambah thermo electric cooling. Dari hasil grafik menunjukkan bahwa system pendingin thermo electric cooling paling efektif dibandingkan dengan heatsink dan water block.

Dengan melihan hasil tersebut rancangan pendingin berbasis mikrokontroler ini dapat sebagai tambahan pengetahuan bahkan dapat dikembangkan untuk memenuhi kebutuhan dan mengatasi permasalahan data/informasi yang banyak dibutuhkan.
\end{abstract}

Kata kunci: Assembler, thermoelectric cooling, heatsink, water block

\section{Pendahuluan}

Sistem pendingin prosesor sebagai bahan uji, pada umumnya hanya menggunakan heatsink dan ditambah dengan fan. Efektifitas sistem pendingin tergantug pada suhu ruang, sehingga pendingan prosesor maksimal akan sama dengan suhu ruang. Dengan demikian perlu dirancang pendingin yang lebih baik dari standar yang ada. Mengingat bahwa pendingin prosesor sangat berpengaruh pada kinerja, manfaat lainnya prosesor tidak cepat rusak. Pendingin yang baik tidak boleh tergantung suhu sekitar atau ruangan sehingga perlu ditambahkan pendingin tambahan agar lebih efektif dan efisien yaitu dengan thermo electric cooling.

\section{Tujuan}

Tujuan perancangan ini untuk memberika gambaran sistem kerja pendingin yang effisien dengan tidak tergantung suhu ruang sekitar. Dengan memanfaatkan Thermo Electric Cooling (TEC1-12706) didalamnya terdiri dari batang Bismuth Telluride kalau diberi tegangan DC 12- 
$15 \mathrm{~V}$ salah satu sisinya menjadi panas dan sisi yang lainnya dingin, dengan perbedaan suhu $65{ }^{\circ} \mathrm{C}$

\section{Metodologi}

1) Alat dan Bahan.Thermo electric cooler is cooling, Microcontroller AT89C51, IC LM 35, A / D Converter, viewer, and Regulator 7805 and supported earth.asm Assembler language.

2) Pengujian setiap komponen agar dapat berfungsi dan sesuai dengan kinerja yang dibutuhkan.

3) Melakukan rancangan perangkat keras sebagai berikut:

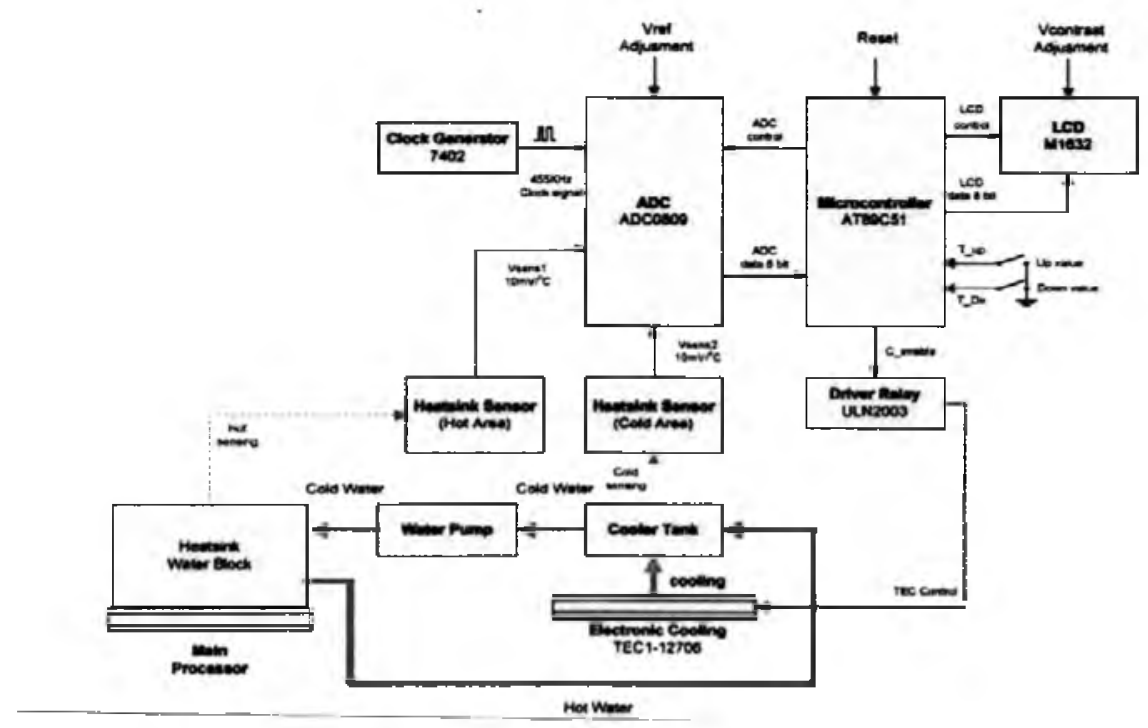

4) Perancangan dan pengujian perangkat lunak Assembler.

\section{Landasan Teori}

1) Sistem Pendingin. Sistem pendingin merupakan suatu cara untuk menjaga suhu suatu komponen elektronik dapat bekerja pada suhu yang diperbolehkan agar dapat bekerja maksimal. Sehingga prosesor harus dijaga suhunya, bahkan dijaga agar suhunya masih dibawah suhu maksimal agar kinerjanya lebih handal. Pembenam panas atau heatsink berfungsi menyerap panas dan mengeluarkan ke udara selanjutnya ditambahkan kipas agar pelepasan ke udara lebih cepat. Material dasar heatsink mempunyai daya hantar bagus sehingga banyak digunakan aluminium dan tembaga. Permukaan heatsink harus luas maka ditambah sirip-sirip untuk menambah luas permukaan. Heatsink dirancang aerodinamis yang bagus agar udara mudah mengalir dan mudah menghantarkan panas dari sumber ke permukaan sirip-sirip serta permukaan heatsink yang kontak dengan panas harus rata supaya dapat terjadi mirror effect.

2) Sistem Kendali. Kontrol PID merupakan algoritma kontrol yang banyak digunakan di industri proses karena bentuknya yang sederhana dan mudah diimplementasikan. Pada kondisi operasi tertentu (seperti misalnya sering terjadi gangguan pada proses atau parameter proses yang berubah-ubah), parameter control ini harus sering di-tuned agar kinerjanya tetap baik. Salah satu teknik dalam sistem kontrol yang sering dilakukan 
untuk mengatasi permasalahan ini adalah dengan menggunakan metode PID Gain Scheduling, dimana parameter kontrol diubah secara otomatis jika terjadi perubahan kondisi operasi yang menyebabkan kinerja kontrol menurun. Penggunaan fuzzy logic di bidang kontrol proses, maka selanjutnya akan dibahas salah satu metode PID gain scheduling dengan menggunakan fuzzy logic. Metode ini dinamakan Fuzzy PID gain scheduling. Fuzzy berfungsi menghitung parameter kontrol PID (Kp, Ti dan Td), berdasarkan kondisi signal error $(\mathrm{E})$ dan perubahan error $(\Delta \mathrm{E})$.

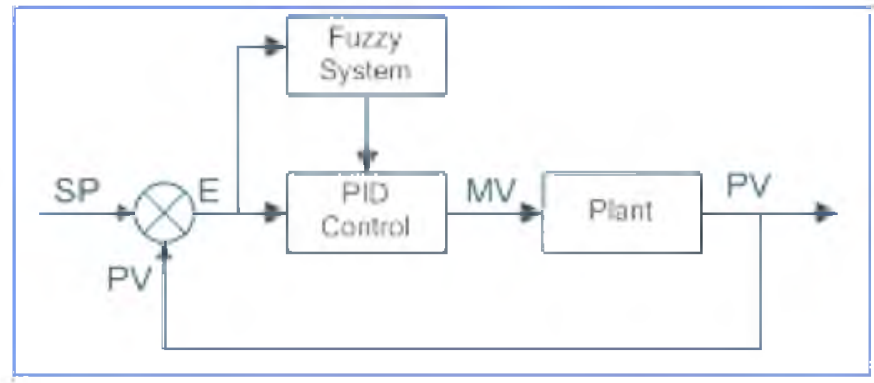

Pada rancangan ini menggunakan pengendali Mikrokontroler AT89C51, merupakan mikrokontroler populer saat ini, telah memiliki flash EPROM kapasitas 4 Kbyte dan dengan memerlukan tambahan tiga kapasitor, satu resistor, dan 1 XTAL untuk dapat bekerja pada tegangan 5 Volt. Mikrokontroler AT89C51 mempunyai 40 pin, 32 pin diantaranya untuk keperluan port parallel 8 bit. Satu port parallel 8 bit sehingga mempunyai 4 port paralel masing-masing port 0 , port 1 , port 2 , dan port 3 .

3) Thermo Electric Cooling (TEC1-12706), merupakan komonen elektronika yang dibungkus dengan keramik tipis didalamnya terdiri dari batang Bismuth Telluride kalau diberi tegangan DC 12-15 V salah satu sisinya menjadi panas dan sisi yang lainnya dingin, dengan perbedaan suhu $65{ }^{\circ} C$. Elektron yang melewati konduktor tembaga dengan memasuki sisi panas melalui semikonduktor $P$, electron akan mengisi hole dan berada pada tingkat energy yang lebih rendah dengan melepaskan panas. Selanjutnya menuju konduktor tembaga pada sisi dingin dan memiliki tingkat energi yang tinggi dengan menyerap panas. Elektron yang melewati konduktor tembaga dengan memasuki sisi dingin melalui semikonduktor $\mathrm{N}$, elektron akan mengeluarkan energi yang besar dengan menyerap panas. Selanjutnya meninggalkan semikonduktor $N$ menuju konduktor tembaga dan memiliki tingkat energi yang rendah dengan melepas panas.

\section{Pengujian peralatan}

1) Pengujian Heatsink dan Cooler Sensor digunakan untuk mengetahui range suhu yang dapat dideteksi LM35 pada saat diaplikasikan pada CPU load 100\%. Tabel Hasil pengujian heatsink dan cooler sensor

\begin{tabular}{|l|l|c|c|l|}
\hline No. & Test Point & Tagangan $V_{d c}$ & Suhu ${ }^{\circ} \boldsymbol{C}$ & Keterangan \\
\hline 1 & Pin INQ & 0,16 & 16 & Suhu Rendah \\
\cline { 3 - 5 } & heatsink & 0,42 & 42 & Suhu Tinggi \\
\hline 2 & Pin IN1 & 0,14 & 14 & Suhu Rendah \\
\cline { 3 - 5 } & cooler & 0,32 & 32 & Suhu Tinggi \\
\hline
\end{tabular}


Dari tabel di atas heatsink dapat mendinginkan prosesor antara $16^{\circ} \mathrm{C}$ sampai dengan $42{ }^{\circ} \mathrm{C}$, sedangkan cooler mendinginkan prosesor antara $14^{\circ} \mathrm{C}$ sampai dengan $32{ }^{\circ} \mathrm{C}$. Dari hasil tersebut bahwa dipasi panas hetsink telah diserap oleh cairan pendingin dan diturunkan suhunya oleh water cooler tank. Cairan pendingin ini disirkulasikan kembali ke heatshink prosesor sehingga digunakan untuk proses pendingan selanjutnya.

2) Pengujian LM35. Untuk mengetahui suhu digunakan thermometer analog sensor LM35 dengan hasil pengujian sebagai berikut: Tabel Hasil Pengujian LM35

\begin{tabular}{|l|c|c|}
\hline No. & $\begin{array}{l}\text { Vout } \\
V_{d c}\end{array}$ & Suhu ${ }^{\circ} \boldsymbol{C}$ \\
\hline 1 & 0,013 & 0 \\
\hline 2 & 0,102 & 10 \\
\hline 3 & 0,204 & 20 \\
\hline 4 & 0,306 & 30 \\
\hline 5 & 0,401 & 40 \\
\hline 6 & 0,505 & 49 \\
\hline 7 & 0,606 & 59 \\
\hline 8 & 0,702 & 68 \\
\hline 9 & 0,804 & 77 \\
\hline 10 & 0,908 & 86 \\
\hline 11 & 1,000 & 96 \\
\hline
\end{tabular}

Dari tabel LM35 tersebut tampak pada suhu 0 sampai $40{ }^{\circ} \mathrm{C}$ adalah linear dan mendekati nilai LM35 satu (titik didih) nilai suhu mempunyai toleransi $4 \%$.

3) Pengujian ADC. Pengujian ADC 0809 untuk mengetahui hasil konversi suhu yang dikirim ke Mikrokontroler sebagai tegangan referensi ADC $V_{\text {ref }}$. Nilai keluaran ADC mempunyai ketepatan $20 \mathrm{mV}$ untuk 1 bit kode LSB.

Tabel Hasil konversi ADC ke 8 bit

\begin{tabular}{|c|c|c|c|l|l|}
\hline No & $\begin{array}{l}\text { Vin ADC } \\
(\mathrm{mV})\end{array}$ & $\begin{array}{l}\text { Keluaran } \\
\text { ADC }\end{array}$ & No & $\begin{array}{l}\text { Vin ADC } \\
(\mathrm{mV})\end{array}$ & $\begin{array}{l}\text { Keluaran } \\
\text { ADC }\end{array}$ \\
\hline 1 & 0 & 00000000 & 11 & 2750,0 & 10001101 \\
\hline 2 & 19,0 & 00000001 & 12 & 3000,0 & 10011010 \\
\hline 3 & 580,0 & 00011110 & 13 & 3240,0 & 10100110 \\
\hline 4 & 1010,0 & 00110100 & 14 & 3490,0 & 10110011 \\
\hline 5 & 1250,0 & 01000000 & 15 & 3750,0 & 11000000 \\
\hline 6 & 1500,0 & 01001101 & 16 & 4000,0 & 11001101 \\
\hline 7 & 1760,0 & 01011011 & 17 & 4230,0 & 11011001 \\
\hline 8 & 2010,0 & 01100111 & 18 & 4490.0 & 11100110 \\
\hline 9 & 2260,0 & 01110100 & 19 & 4760,0 & 11110100 \\
\hline 10 & 2500,0 & 10000000 & 20 & 4980,0 & 11111111 \\
\hline
\end{tabular}


Sedangkan pengujian clock generator adalah melalui pin CLOCK ADC dengan nilai tegangan DC 0,5 V kondisi $\mathrm{L}(\mathrm{low})$ dan $4,8 \mathrm{~V}$ pada kondisi $\mathrm{H}$ (high). Clock tersebut dihasilkan dari frekuensi komponen Kristal resonator $455 \mathrm{kHz}$ dengan nilai toleran si $3 \%$.

4) Pengujian Mikrokontroler dan LCD. Pengujian Mikrokontroler dan LCD untuk mengetahui status tegangan pada Reset, XTal1, XTal2, serta kontras LCD $\left(V_{E E}\right)$ yang sesuai dengan Tabel berikut: Tabel Hasil Pengujian Mikrokontroler dan LCD.

\begin{tabular}{|l|l|c|l|}
\hline No. & Test Point & $\begin{array}{c}\text { Tegangan } \\
\boldsymbol{V}_{\boldsymbol{d} \boldsymbol{c}}\end{array}$ & \multicolumn{1}{|c|}{ Keterangan } \\
\hline 1 & \multirow{2}{*}{ Pin RST } & 0 & Reset, pasif \\
\cline { 3 - 4 } & & 4,98 & Reset, aktif \\
\hline 2 & Pin XTAL1 & 2,14 & Tegangan XTAL1 \\
\hline 3 & Pin XTAL2 & 2,26 & Tegangan XTAL2 \\
\hline 4 & Pin $V_{\boldsymbol{E} \boldsymbol{E}}$ & 0,86 & Tegangan $\boldsymbol{V}_{\boldsymbol{E} \boldsymbol{E}}$ \\
\hline
\end{tabular}

Dari Tabel tersebut tegangan reset aktif mencapai $4,98 \mathrm{~V} \mathrm{dc}$, dan mikrokontroler dapat membaca logika 1 pada nilai masukan tegangan 3,5 Vdc. Dengan kapasitor $10 \mu \mathrm{F}$ dan resistor $8 \mathrm{k} \Omega$ dengan waktu tunda resetnya sebesar 14,68 milisekon.

5) Pengujian Driver Relay. Pengujian Driver Relay dipakai untuk mengetahui aktifitas pada saat mengendalikan relay dan fan berdasar status kontrol yang terhubung. Tabel Hasil pengujian driver relay

\begin{tabular}{|l|l|c|l|}
\hline No. & \multicolumn{1}{|c|}{ Test Pint } & $\begin{array}{c}\text { Tegangan } \\
V_{d c}\end{array}$ & \multicolumn{1}{|c|}{ Keterangan } \\
\hline 1 & Pin 4B Cooler & 4,98 & Relay cooler, ON \\
\cline { 3 - 4 } & ON/OFF & 0,02 & Relay cooler,OFF \\
\hline 2 & \multirow{2}{*}{ Pin 4C Relay } & 0,02 & Relay, ON \\
\cline { 3 - 4 } & & 12,14 & Relay, OFF \\
\hline 3 & \multirow{2}{*}{ Pin 5B Fan ON/OFF } & 4,98 & Kontrol fan, ON \\
\cline { 3 - 4 } & & 0,02 & Kontrol fan,OFF \\
\hline 4 & Pin 5C Motor Fan & 0,02 & Fan, ON \\
\cline { 3 - 4 } & & 12,14 & Fan, OFF \\
\hline
\end{tabular}

Dari tabel tersebut jika Cooler dan Fan kondisi tinggi $\mathrm{H}^{\text {" }} \mathrm{ON}^{\prime \prime}$ dan saluran keluaran Relay dan Motor Fan kondisi rendah $\mathrm{L}^{\text {"OFF" }}$, proses pengendalian akan tembus lilitan internal relay dan motor fan akan disalurkan ke GND. Sehingga akan terjadi beda potensial antara relay dan motor fan sehingga akan kondisi hidup. Sebaliknya Cooler dan Fan kondisi rendah $\mathrm{L}^{\text {"OFFF }}{ }^{x}$ dan saluran keluaran Relay dan Motor Fan kondisi tinggi $\mathrm{H}$ "ON", proses pengendalian akan tembus lilitan internal Relay dan motor fan tidak akan disalurkan ke GND. Sehingga tidak terjadi beda potensial antara relay dan motor fan sehingga akan kondisi mati. Relay dengan resistor internal $120 \Omega$ dengan tegangan 12 Vdc sehingga arusnya 101,167 mA, sedangkan motor fan dengan resisto 25 dengan tegangan $12 \mathrm{Vdc}$ arus $216,78 \mathrm{~mA}$. 
5) Pengujian Catu Daya. Pengujian Catu Daya untuk mengetahui rangkaian dengan beban dan tanpa beban pada rangkaian lengkap dengan hasil sebagai berikut:

\begin{tabular}{|l|l|c|l|}
\hline No. & Test Point & $\begin{array}{c}\text { Tegangan } \\
V_{d c}\end{array}$ & \multicolumn{1}{|c|}{ Keterangan } \\
\hline 1 & Pin Vin & 12,34 & Vss Tanpa Beban \\
\hline 2 & Pin Vin & 12,14 & Vss Dengan Beban \\
\hline 3 & Pin Vout & 5,04 & Vcc Tanpa Beban \\
\hline 4 & Pin Vout & 5,00 & Vcc Dengan Beban \\
\hline
\end{tabular}

Dari tabel Vss tanpa beban tegangan lebih tinggi dari dengan beban dengan kerugian tegangan $2 \%$ dan Vcc dengan rugi tegangan $1 \%$.

\section{Hasil Rancangan}

1) Simulasi rancangan system, pendingin berbasis mikrokontroler dengan menggunakan aplikasi yang dijalankan oleh PC dengan top load performa 100\%. Dengan kondisi tiga kategori Heatsink Standar dengan Fan, Water Block tanpa Thermoelectric Cooling, dan Water Block dengan Thermoelectric Cooling dengan hasil sebagai berikut:

\begin{tabular}{|c|c|c|c|c|c|c|c|}
\hline \multirow[t]{2}{*}{ No } & \multicolumn{3}{|c|}{ Suhu Prosesor ${ }^{\circ} \mathrm{C}$} & \multicolumn{3}{|c|}{ Suhu Indikator $\operatorname{LCD}{ }^{\circ} \mathrm{C}$} & \multirow{2}{*}{$\begin{array}{l}\text { Waktu } \\
\text { (menit) }\end{array}$} \\
\hline & $\begin{array}{l}\text { Model } \\
1\end{array}$ & $\begin{array}{l}\text { Model } \\
2\end{array}$ & $\begin{array}{l}\text { Model } \\
3\end{array}$ & Model 1 & $\begin{array}{l}\text { Model } \\
2\end{array}$ & $\begin{array}{l}\text { Model } \\
3\end{array}$ & \\
\hline 1 & 31 & 28 & 28 & 33 & 30 & 30 & 0 \\
\hline 2 & 40 & 35 & 34 & 34 & 32 & 32 & 3 \\
\hline 3 & 41 & 36 & 35 & 35 & 33 & 32 & 6 \\
\hline 4 & 41 & 37 & 35 & 35 & 34 & 32 & 9 \\
\hline 5 & 41 & 38 & 35 & 35 & 34 & 32 & 12 \\
\hline 6 & 41 & 38 & 36 & 35 & 35 & 32 & 15 \\
\hline 7 & 41 & 39 & 36 & 35 & 35 & 33 & 18 \\
\hline 8 & 41 & 39 & 36 & 35 & 36 & 33 & 21 \\
\hline 9 & 41 & 40 & 36 & 35 & 36 & 33 & 24 \\
\hline 10 & 41 & 40 & 36 & 35 & 36 & 33 & 27 \\
\hline 11 & 41 & 40 & 36 & 35 & 36 & 33 & 30 \\
\hline 12 & 41 & 41 & 36 & 35 & 37 & 33 & 33 \\
\hline 13 & 41 & 41 & 37 & 35 & 37 & 33 & 36 \\
\hline 14 & 41 & 41 & 37 & 35 & 37 & 33 & 39 \\
\hline 15 & 41 & 41 & 37 & 35 & 37 & 33 & 42 \\
\hline 16 & 41 & 41 & 37 & 35 & 37 & 33 & 45 \\
\hline 17 & 41 & 41 & 37 & 35 & 37 & 33 & 48 \\
\hline 18 & 41 & 41 & 37 & 35 & 37 & 33 & 51 \\
\hline 19 & 41 & 41 & 37 & 35 & 37 & 33 & 54 \\
\hline 20 & 41 & 41 & 37 & 35 & 37 & 33 & 57 \\
\hline 21 & 41 & 41 & 37 & 35 & 37 & 33 & 60 \\
\hline
\end{tabular}




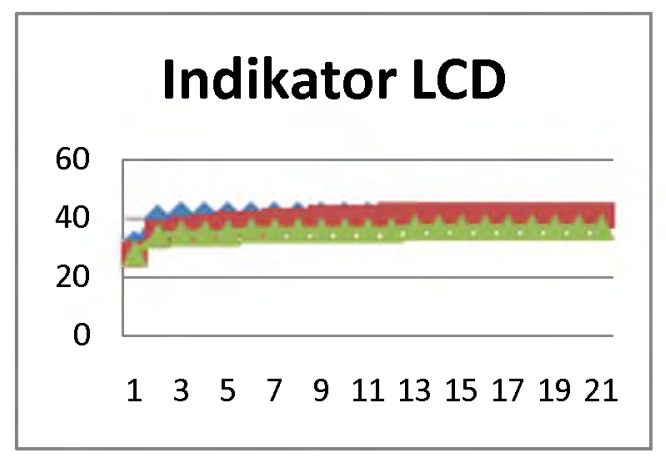

(a)

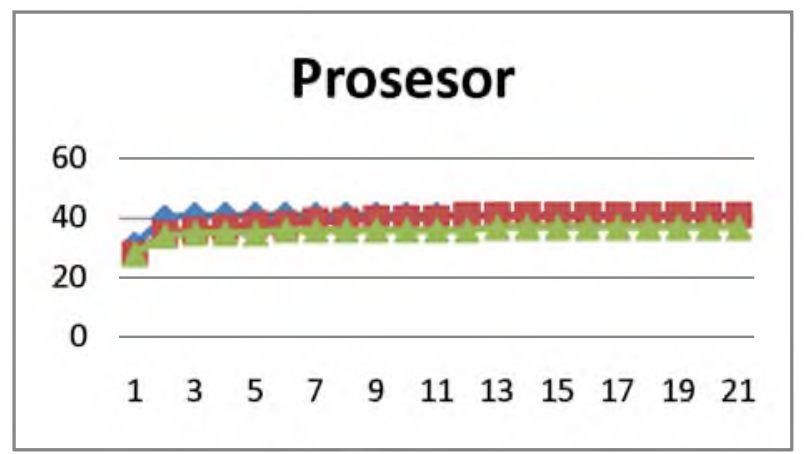

(b)

Gambar 1. (a) Grafik suhu pada tampilan LCD (b) Grafik suhu pada Prosesor

\section{2) Diagram Rancangan}

Berikut ini blok diagram keseluruhan dari sistem pendingin berbasis mikrokontroler

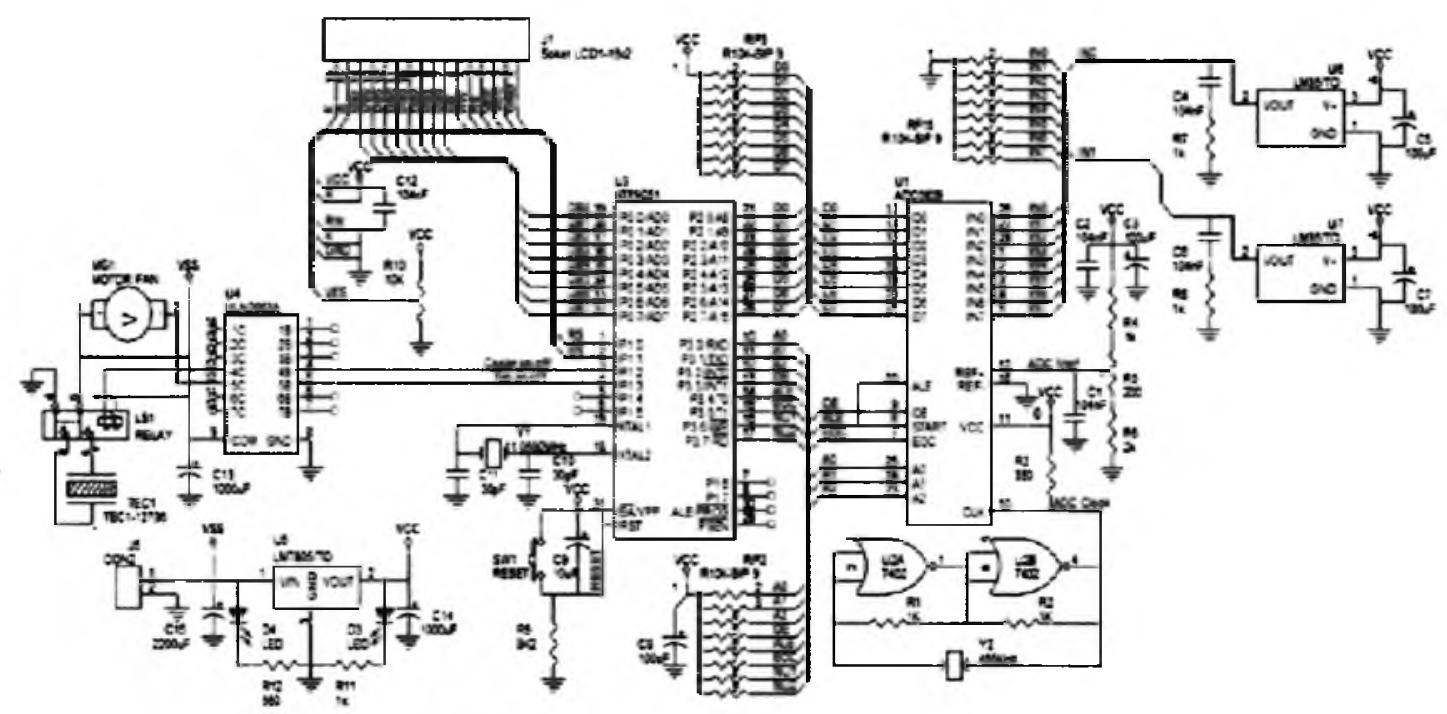

\section{Kesimpulan}

Thermo electric cooling sebagai pendingin dengan dukungan Mikrokontroler sebagai pengendali otomatis dapat diambil kesimpulan:

1) Rancangan dapat dimanfaatkan pada sistem pengendalian peralatan, kinerja sistem terpengaruh panas, bekerja pada suhu tinggi, serta dapat dikendalikan.

2) Hasil pengujian komponen LM35 suhu 0 sampai $40^{\circ} \mathrm{C}$ adalah linear dan mendekati nilai satu (titik didih) dengan toleransi $4 \%$.

3) Hasil simulasi dan grafik pada tiga keadaan kondisi suhu prosesor dan heatsink prosesor pertama menggunakan heatsink standar, kedua water block dan ketiga water block ditambah thermo electric cooling. Dari hasil grafik menunjukkan bahwa system pendingin thermo electric cooling paling efektif dibandingkan dengan heatsink dan water block. 


\section{Saran}

Rancangan pendingin berbasis mikrokontroler ini dapat sebagai tambahan pengetahuan bahkan dapat dikembangkan untuk memenuhi kebutuhan serta diaplikan pada sistem dengan pendalian otomatis

\section{Daftar Pustaka}

Andi W., 2008, Mikrokontroler AVR ATmega8/32/16/8535 dan Pemrogramannya dengan Bahasa C pada WinA VR, Informatika, Jakarta

Agfianto E.p., 2002, Belajar Mikrokontroler AT89C 51/52/55, Gava Media, Yogyakarta.

Balza A., Wahyu S., 2008, Sistem Alram Mobil Menggunakan Mikrokontroler AT89C52 Berbasis SMS, Tekomnika, Vol 6 No.1, April 2008, UAD Yogyakarta.

Benedictus B. S., 2005, Belajar Alarm Berbasis Sensor Getaran, PT. ElekMedia Komputindo, Jakarta

Roger L. Tokheim, 1995, Elektronika Digital, Erlangga, Jakarta

Widodo B. H., 2004, Elektronika Digital dan Mikroprosesor, Andi, Yogyakarta

Widodo B. H., 2004, Interfacing Computer dan Mikrokontroler, PT Elekmedia Komputindo, Jakarta 